Психология. Журнал Высшей школы экономики.

2010. T. 7, № 3. С. 120-128.

Короткие сообщения

\title{
САМООЦЕНКА ЭМОЦИОНАЛЬНОГО ИНТЕЛЛЕКТА С ТОЧКИ ЗРЕНИЯ МОДЕЛИ КУЛЬТУРНОЙ РЕЛЕВАНТНОСТИ
}

\author{
Л.Д. КАМЫШНИКОВА, С.С. БЕЛОВА
}

\begin{abstract}
Резюме
Исследование посвящено изучению спечифики самооценки эмоционального интеллекта (ЭИ), которая рассматривалась с позиций теоретической модели релевантности задачи культуре. Модель включает в себя три измерения (прототипичность, ценность, частотность) и предполагает их влияние на внешнюю валидность самооценки. На первом этапе исследования был сконструирован опросник ЭИ на основе подхода Д. Басса и К. Крейка. На втором этапе пункты опросника были оченены с точки зрения трех измерений релевантности. На третьем этапе проведено измерение ЭИ с помощью сконструированного опросника и тестов. Показано, что коррелящия пунктов опросника ЭИ с внешними критериями предсказывается их ценностью (с положительным знаком). Уровень самооценки в большей степени, по сравнению с ее точностью, определяется релевантностью.
\end{abstract}

Ключевые слова: самооценка эмоционального интеллекта, гендерные различия, прототип, культурная релевантность.

Самооценка по психологическому опроснику - явление насколько важное для изучения индивидуальных различий, настолько и дискуссионное. С одной стороны, в психо- логии личности и мотивации самоотчет о своих психологических характеристиках остается широко используемым методом получения данных, ему сложно подобрать альтернативу.

Исследование выполнено при финансовой поддержке ФЦП «Научные и научно-педагогические кадры инновационной России» на 2009-2013 гг., ГК № П 1014 от 20.08.2009 г. 
С другой стороны, точность такого измерения относительна: действие факторов социальной желательности, культурной и социально-демографической специфики восприятия содержания методики приводит к весьма приблизительной оценке психологической черты.

Для психологии эмоционального интеллекта (далее - ЭИ) эта проблема также является актуальной. В этой области выделяют два ключевых подхода: один трактует ЭИ как способность, измеряемую тестами, второй определяет его как более разнородное образование, включающее как способности, так и эмоционально-социальную компетентность, личностные особенности, вследствие чего для его оценки используются многочисленные методы самоотчета (см. обзор: Робертс и др., 2004). Критериальная валидность опросников в сравнении с тестами ЭИ оценивается в целом как удовлетворительная по отношению к разным аспектам жизненных достижений, в связи с чем изучение определяющих ее факторов представляется заслуживающим внимания.

В настоящем исследовании предпринята попытка рассмотреть самооценку ЭИ через призму подхода, предполагающего фиксацию особенностей восприятия проявлений ЭИ в поведении и их влияние на самооценку. Данный подход имеет истоки в так называемой стратегии прототипов, предложенной М. Амелангом с соавт. (Amelang et al., 1991). Они показали, что самооценка по пунктам опросника креативности, являвшимся для испытуемых более яркими примерами прототипа творческого поведения, оказалась более валидной по отношению к соответствующему внешнему критерию. Прототипичность пункта опросника может быть определена как степень его меткости в обозначении конструкта для испытуемого. Например, пункт «Я делаю мебель из предметов, найденных на свалке» в данной работе был оценен как более прототипичный для креативности, чем пункт «Когда я заболеваю, то пробую разные способы лечения».

В дальнейшем стратегия прототипов получила свое развитие в так называемой модели релевантности задачи культуре Д.В. Ушакова, дополнившего подход двумя новыми измерениями - частотностью и ценностью (Белова и др., 2008). Если прототипичность представляет собой показатель того, насколько хорошим примером для конструкта способности является то или иное действие/поведение, описанное в пункте опросника, то частотность отражает распространенность действия, ценность - его мотивационную привлекательность. Было высказано предположение, что для представителей разных культурных сред любой пример деятельности, способности к которому могут быть оценены самим человеком, будет иметь культурноспецифичную оценку по указанным измерениям релевантности. Предсказательные возможности модели были изучены в отношении функционирования опросников интеллекта и креативности в кросскультурном российско-немецком исследовании (Белова, Валуева, 2008). В частности, было показано, что пункты опросника интеллекта, имеющие сходные оценки по измерениям релевантности, коррелируют между собой сильнее, 
чем пункты с различающимися оценками, а измерения прототипичности и ценности связаны соответственно положительно и отрицательно с внешней валидностью опросника.

Самооценка ЭИ в подобном ключе ранее не изучалась. Логично допустить, что способности, связанные с управлением своими эмоциями и пониманием других людей, в представлении испытуемых выделяются в особый класс, образуя некоторую имплицитную теорию того, что в научной психологии определяется как ЭИ. Для обыденной психологии идея деления людей на тех, кто умеет эффективно общаться и справляться с эмоциональными переживаниями, и тех, кому это удается в меньшей степени, интуитивно понятна. Можно предположить, что представление о подобных способностях является основой определенной логики их самооценки и связано с ее точностью. Прототипичность - лишь одно из возможных измерений, позволяющих выделить существенное в представлении об ЭИ. В настоящем исследовании мы обращаемся к вышеописанной модели, предполагающей два дополнительных измерения - частотность и ценность. Их выделение в качестве существенных для самооценки способностей (как общих, так и эмоциональных или социальных) строится на соображении, что частотность может отражать опыт вложения усилий в данную область задач или их сложность, а ценность - субъективное эмоционально окрашенное отношение к ним. Для оценки того, существует ли влияние специфики представлений об ЭИ, зафиксированной в виде оценок трех измерений релевантности, на точность его самооценки, был сконструирован опросник ЭИ и оценена его внешняя валидность.

\section{Метод}

Исследование состояло из трех этапов сбора данных.

Цель первого этапа заключалась в разработке опросника ЭИ на основе подхода Д. Басса и К. Крейка, согласно которому содержание пункта опросника должно представлять собой пример поведения/действия в некотором ситуационном контексте, частотность которого испытуемый оценивает в отношении себя (Buss, Craik, 1983). В соответствии с методологией данного подхода, испытуемых просили привести описания конкретных примеров поведения в определенных ситуациях, свидетельствующие, по их мнению, о высоком уровне развития способности:

- строить взаимоотношения;

- управлять своими эмоциями и эмоциями других людей;

- понимать эмоции;

- точно оценивать и выражать эмоции.

Было получено 160 примеров поведения, которые были подвергнуты редактированию, что позволило их использовать в качестве утверждений опросника ЭИ.

Цель второго этапа состояла в выявлении оценки прототипичности, частотности и ценности каждого пункта разработанного опросника ЭИ. Полученные оценки позволяют в дальнейшем рассматривать отдельно подгруппы пунктов опросника, различные в том или ином отношении, и фиксировать их психометрические свойства. Испытуемым 
были заданы следующие вопросы относительно примеров поведения, составлявших пункты опросника:

- для оценки частотности: насколько часто молодые люди вашего возраста демонстрируют такое поведение?

- для оценки ценности: насколько ценным является такое поведение в нашем обществе?

- для оценки прототипичности: насколько типичным является каждый пример поведения для человека, умеющего понимать и чувствовать людей?

Цель третьего этапа заключалась в сборе данных с помощью разработанного опросника ЭИ, вербальной, невербальной и самоотчетной методик ЭИ; диагностировались общий интеллект и личностные особенности.

Методики: разработанный опросник ЭИ, опросник Д.В. Люсина ЭмИн (Люсин, 2006), опросник NEO-FFI для оценки факторов модели Большая пятерка (адаптация М.В. Бодунова, С.Д. Бирюкова), видеотест способности к распознаванию эмоций В.В. Овсянниковой, Д.В. Люсина (Овсянникова, 2007), методика оценки чувствительности к эмоциональной окрашенности слов Е.В. Теплякова (Тепляков, 2009), тест Продвинутые прогрессивные матрицы, серия II (Равен и др., 1998). Использовались следующие показатели и их обозначения:

1. Опросник ЭИ (сумма баллов по разработанному опроснику ЭИ; ЭИ)

Шкаль опросника ЭмИн:

2. Межличностное понимание эмоuцй (МП)

3. Межличностное управление эмоциями (МУ)
4. Внутриличностное понимание әмоиий (ВП)

5. Внутриличностное управление әмочиями (ВУ)

6. Контроль экспрессии (ВЭ)

7. Межличностный ЭИ (МЭИ)

8. Внутриличностный ЭИ (ВЭИ)

9. Понимание эмоций (ПЭ)

10. Управление эмоциями (УЭ)

Шкаль опросника NEO-FFI:

11. Нейротизм (H)

12. Экстраверсия (Э)

13. Открылость опьту (O)

14. Доброжелательность (Д)

15. Сознательность (C)

Показатели видеотеста:

16. Видеотест точность (ВТ)

17. Сензитивность к отрицательной валентности эмоций (СенО)

18. Сензитивность к положительной валентности эмоций (СенП)

19. Сензитивность к активации ( СенА)

Другие

20. Тест эмоциональных слов (общий балл по методике оценки чувствительности к эмоциональной окрашенности слов, ТЭС)

21. ППМ (общий балл)

Испьтуемые. На первом этапе исследования приняли участие 91 человек (из них 55 - женщины), студенты Первого МГМУ им. И.М. Сеченова, средний возраст - 24 года.

На втором этапе были получены оценки прототипичности $(\mathrm{N}=32$, из них 23 женщины), частотности ( $\mathrm{N}=39$, из них 33 женщины), ценности ( $\mathrm{N}=34$, из них 28 женщин). Испытуемыми выступили студенты Первого МГМУ им. И.М. Сеченова, средний возраст - 23 года. Разные группы респондентов оценивали каждое из измерений. 
На третьем этапе участвовали 182 испытуемых (из них 82 женщины), студенты Технологического колледжа № 28 г. Москвы и Первого МГМУ им. И.М. Сеченова, средний возраст - 17.2 года.

\section{Результаты исследования}

\section{Общая характеристика разработанного опросника ЭИ}

Разработанный опросник состоял из 116 пунктов с положительной нагрузкой. Испытуемые оценивали степень того, насколько описанные примеры поведения характерны для них, используя пятибалльную шкалу (от 1 - «совсем не подходит» до 5 «очень подходит»).

Корреляционный анализ данных выявил наличие значимых взаимосвязей между самооценкой по разработанному опроснику и другими методиками самооценки (таблица 1). Так, с опросником ЭмИн выявлены значимые положительные корреляции со всеми шкалами, за исключением субшкалы Контроль экспрессии $(r=0.03$, н/знач). Наиболее тесные связи образованы со шкалой Межличностного ЭИ $\left(r=0.64^{* *}\right)$ и шкалой Понимания чужих эмоций $\left(r=0.6^{* *}\right)$. Со шкалами, релевантными внутриличностному ЭИ, корреляции несколько ниже: $r=0.29^{* *}$ (Понимание своих эмоций), $r=0.4^{* *}$ (Управление своими эмоциями), $r=0.3^{* *}($ Внутриличностный ЭИ).

Выявлены значимые взаимосвязи со всеми шкалами опросника NEO-FFI: связь с Нейротизмом отрицательна $\left(r=-0.31^{* *}\right)$, с остальными измерениями - положительна. Коэффици- енты корреляции с Экстраверсией составили $0.47^{* *}$, с Открытостью $0.24^{* *}$, с Доброжелательностью $0.38^{* *}$, с Сознательностью - $0.45^{* *}$.

Выявлено отсутствие взаимосвязи между самооценкой по разработанному опроснику и продуктивностью по тесту общего интеллекта $(r=0.05$, н/знач); эффективностью выполнения методики оценки чувствительности к эмоциональной окрашенности слов $(r=0.08$, н/знач $)$. В отношении видеотеста способности к распознаванию эмоций получены положительные связи с показателями Сензитивности к положительной валентности эмоций $\left(r=0.17^{*}\right)$ и Сензитивности к высокой активации $\left(r=0.16^{*}\right)$. Связи с Точностью и Сензитивностью $\kappa$ отрицательной валентности эмоций не выявлены.

\section{Взаимосвязь измерений релевантности с внешней валидностью опросника ЭИ}

Оценки измерений релевантности пунктов опросника ЭИ характеризовались высокой внутренней согласованностью. Коэффициенты $\alpha$-Кронбаха составили для прототипичности 0.89 , для ценности 0.84 , для частотности -0.88 .

Для проверки гипотезы о детерминации психометрических свойств пунктов опросника их релевантностью был проведен обратный пошаговый множественный регрессионный анализ в целом по выборке и для подгрупп мужчин и женщин.

Независимыми переменными выступили измерения релевантности: средние оценки ценности, частотности, прототипичности для каждого пункта опросника. В подсчетах для 


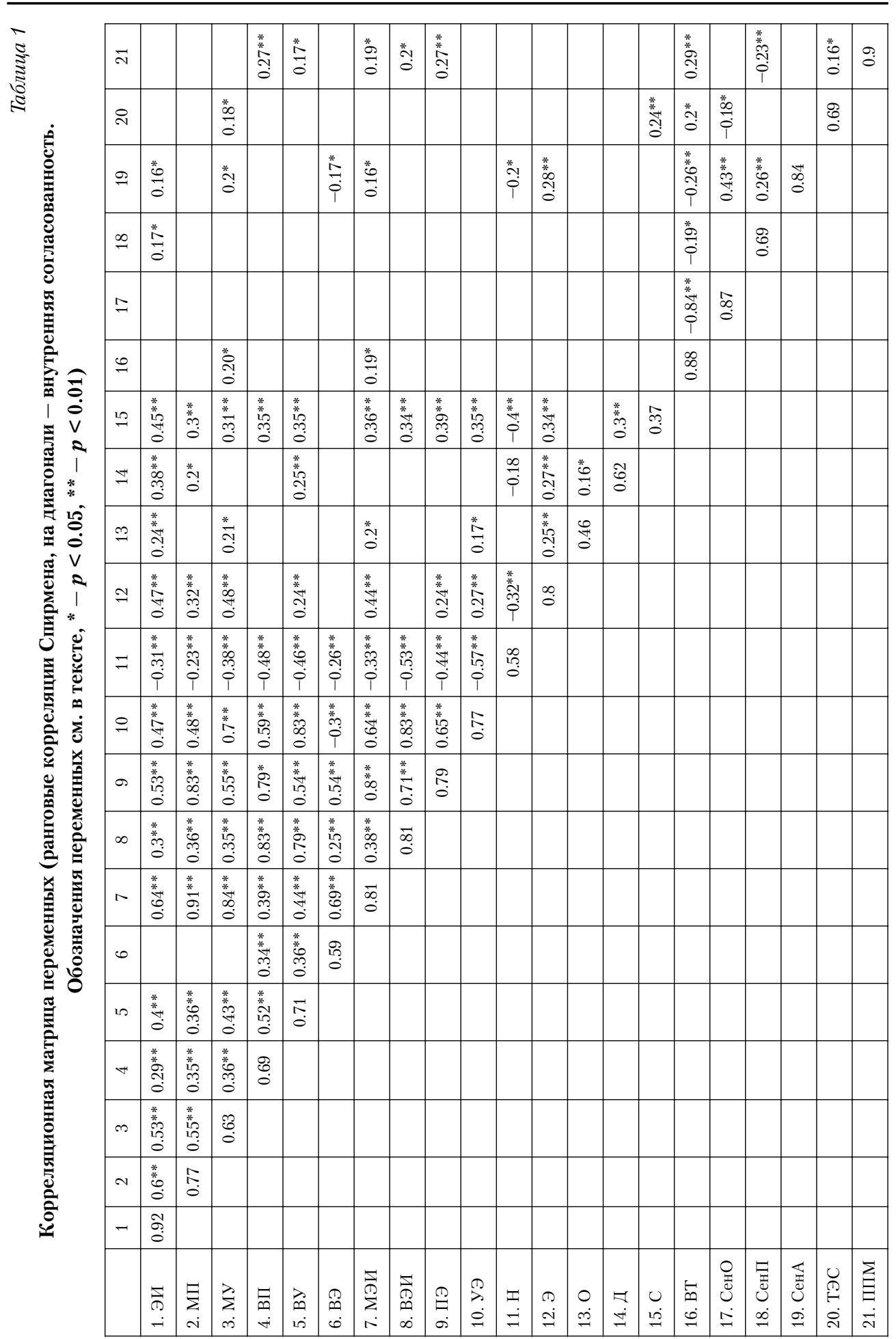


подгрупп мужчин и женщин использовались средние оценки измерений релевантности, полученные на мужской и женской выборках 2-го этапа.

Зависимой переменной являлись коэффициенты корреляции каждого пункта с показателем тестового ЭИ (средним z-оценок точности по видеотесту и общего балла по методике оценки чувствительности к эмоциональной окрашенности слов). Результаты регрессионного анализа представлены в таблице 2.

В целом по выборке самооценка по пунктам, содержащим описание более ценных, с точки зрения испытуемых, примеров поведения, оказалась в большей степени валидной по отношению к тестовому ЭИ $\left(R^{2}=\right.$ $=0.124, \beta$ (ценность $)=0.352, p<0.001)$. Процент объясняемой дисперсии оказался сравнительно невысоким. Для сопоставления в случае рассмотрения опросников интеллекта и креативности с позиции модели релевантности коэффициенты детерминации составили 0.31 и 0.35 соответственно, а ценность вошла в модель с отрицательным $\beta$-коэффициентом (наряду с прототипичностью, имевшей положительный знак) (Белова, Валуева, 2008).

Не выявлена взаимосвязь между точностью самооценки ЭИ женщи- нами и их оценками релевантности пунктов опросника, в то время как в подгруппе мужчин точность самооценки предсказывалась прототипичностью.

\section{Взаимосвязь измерений релевантности с уровнем самооценки по опроснику ЭИ}

Мы также рассмотрели вопрос о том, как связаны оценки релевантности пунктов с уровнем самооценки по опроснику ЭИ. Был проведен обратный пошаговый множественный регрессионный анализ, в котором независимыми переменными выступили средние оценки измерений релевантности пунктов, а зависимой - средняя оценка по пункту опросника. Результаты для мужской и женской подгрупп представлены в таблице 3.

Данные свидетельствуют, что 63\% и $54 \%$ дисперсии в уровне самооценки ЭИ мужчин и женщин соответственно предсказывались измерениями релевантности. Обращают на себя внимание два факта: 1) более высокие коэффициенты детерминации регрессионных моделей по сравнению с моделями, рассматривавшими внешнюю валидность опросника; 2) различие в наборе предикторов

Таблища 2

Результаты множественного регрессионного анализа (ЗП - корреляция пунктов с тестовым ЭИ, НП - оценки релевантности пунктов опросника ЭИ)

\begin{tabular}{|l|c|c|c|c|}
\hline \multirow{2}{*}{ Группы испытуемых } & \multirow{2}{*}{$\boldsymbol{R}^{2}$} & \multicolumn{3}{|c|}{$\boldsymbol{\beta}$-коэффициенты НП и их значимость (в скобках) } \\
\cline { 3 - 5 } & & Прототипичность & Ценность & Частотность \\
\hline Вся выьборка $(N=182)$ & 0.124 & & $0.352(<0.001)$ & \\
\hline Мужчины $(N=100)$ & 0.156 & $0.395(<0.001)$ & & \\
\hline Женщины $(N=82)$ & 0.032 & & $0.179(0.055)$ & \\
\hline
\end{tabular}


Результаты множественного регрессионного анализа (ЗП - средний балл по пункту, НП - оценки релевантности пунктов опросника)

\begin{tabular}{|l|c|c|c|c|}
\hline \multirow{2}{*}{ Группы испытуемых } & \multirow{2}{*}{$\boldsymbol{R}^{2}$} & \multicolumn{3}{|c|}{$\boldsymbol{\beta}$-коэффициенты НП и их значимость (в скобках) } \\
\cline { 3 - 5 } & & Прототипичность & Ценность & Частотность \\
\hline Вся выборка $(N=182)$ & 0.666 & $0.247(0.003)$ & $0.256(0.001)$ & $0.434(<0.001)$ \\
\hline Мужчины $(N=100)$ & 0.629 & $0.672(<0.001)$ & & $0.282(<0.001)$ \\
\hline Женщины $(N=82)$ & 0.537 & $0.261(<0.001)$ & $0.375(<0.001)$ & $0.342(<0.001)$ \\
\hline
\end{tabular}

между мужчинами и женщинами: при универсальной тенденции оценивать себя более высоко по более частотным и более прототипичным пунктам выявлена ориентация женщин также на ценностное измерение.

Результаты, касающиеся гендерных различий в детерминации внешней валидности и уровня самооценки измерениями релевантности, рассматриваются нами как предварительные в связи с малым объемом выборки в подгруппах мужчин и женщин, оценивавших измерения релевантности на втором этапе сбора данных.

\section{Выводы}

1. Выявлены значимые положительные взаимосвязи опросника ЭИ, разработанного на основе подхода Д. Басса и К. Крейка, с данными самооотчета о личностных особенностях и ЭИ и отсутствие связей с тестовыми показателями ЭИ и общего интеллекта.

2. Связь специфики представлений об ЭИ с внешней валидностью его самооценки заключается в том, что самооценка по более ценными в восприятии испытуемых пунктам опросника является более точной по отношению к тестовому ЭИ как внешнему критерию.

3. Специфика представлений о проявлениях ЭИ в поведении, описанных с помощью трех измерений прототипичности, ценности и частотности, в большей степени связана с уровнем самооценки, чем с ее внешней валидностью.

\section{Литература}

Белова С.С., Валуева Е.А., Ушаков Д.В. Психодиагностика способностей: Проблема релевантности метода культуре // Современная психодиагностика в изменяющейся России: Сборник тезисов всероссийской научной конференции / Ред- коллегия: Н.А. Батурин (отв. ред.) и др. Челябинск: Изд-во ЮУрГУ, 2008. C. 9-12.

Белова С.С., Валуева Е.А. Проблемы культурной релевантности оценки интеллекта и креативности // Материалы 
итоговой научной сессии ИП РАН. М.: Изд-во ИП РАН, 2008. С. 49-63.

Люсин Д.В. Новая методика для измерения эмоционального интеллекта: опросник ЭмИн // Психологическая диагностика. 2006. № 4. С. 3-22.

Овсянникова В.В. Роль когнитивных факторов в субъективной оценке эмоционального состояния: Дис. ... канд. психол. наук. М., 2007.

Равен Дж.К., Курт Дж.Х., Равен Дж. Руководство к прогрессивным матрицам Равена и словарным шкалам. Разд. 4. Продвинутые Прогрессивные Матрицы: М.: Когито-Центр, 1998.

Робертс Р.Д., Мэттьюс Дж., Зайднер М., Люсин Д.В. Эмоциональный интеллект: проблемы теории, измерения и примене- ния на практике // Психология. Журнал Высшей школы экономики. 2004. Т. 1, № 4. C. 3-26.

Тепляков E.B. Разработка комплекса методик диагностики особенностей переработки эмоциональной информации: Отчет о научно-исследовательской работе лаборатории диагностики одаренности. М.: Московский городской психолого-педагогический университет, 2009. C. 27-28.

Amelang M., Herboth G., Oefne I. A prototype strategy for the construction of a creativity scale // European Journal of Personality. 1991. 5. 261-285.

Buss D., Craik K. The act frequency approach to personality // Psychological Review. 1983. 2. 105-126.

Камышникова Любовь Дмитриевна, аспирант Института психологии РАН Контакты: lubrster@gmail.com

Белова Софья Сергеевна, научный сотрудник Института психологии РАН, заведующая лабораторией МГППУ, кандидат психологических наук

Контакты: sbelova@gmail.com 